\title{
Söz Uçar, Yazı Dikkat Çeker: Resimli Çocuk Kitapları Kapsamında Erken Yazı Farkındalığı*
}

\author{
Elif KURAL'1, Fatma Merve ŞiMŞEK²
}

\begin{abstract}
Öz: Dikkati yazıya çeken özellikler resimli çocuk kitapları aracılı̆̆ıla örneklendirilmiş ve kitapların bu özelliklerden hangisini kapsadığı belirlenmiştir. Uygun örnekleme ile seçilen 59 resimli çocuk kitabına doküman incelemesi yapılmış ve oluşturulan alt temalar ve kategorilere göre kitapların sahip olduğu özellikler belirlenmiştir. Kitapların dikkati yazıya çeken özellikler teması kapsamında betimsel analizi yapılmıştır. Görseldeki yazı alt teması; etiketler, çevresel yazı, konuşmanın gösterimi, sesin gösterimi ve harfin gösterimi kategorilerine ayrılırken metindeki yazı alt teması yazı biçimi değişikliği ve özel yazı tipi kullanımı kategorilerine ayrılmıştır. Dikkati yazıya çeken özelliklere ait kategoriler altında toplanan kitap sayısı şöyledir: Etiketler kategorisinde 32 tane kitap, çevresel yazı kategorisinde 40 tane kitap, konuşmanın gösterimi kategorisinde 16 tane kitap, sesin gösterimi kategorisinde 26 tane kitap, harfin gösterimi kategorisinde 9 tane kitap, yazı biçimi değişikliği kategorisinde 52 tane kitap, özel yazı tipi kullanımı kategorisinde 29 tane kitap. İncelenen kitaplarda en sık yazı biçimi değişikliği ve çevresel yazı özelliklerine rastlanırken en az rastlanan özellik harfin gösterimi olmuştur.
\end{abstract}

Anahtar Kelimeler: Yazı olarak niteleme, Dikkati yazıya çeken özellikler, Erken yazı farkındalığı, Resimli çocuk kitapları, Erken çocukluk

\section{Words Fly Away, Print Salients Stay: Early Print Awareness within the Scope of Children's Picture Books}

\begin{abstract}
Print salient features were exemplified through children's picture books and it was determined which of these features the books included. The characteristics of the books were determined according to sub-themes and categories by document analysis of 59 children's picture books determined by purposive sampling. Descriptive analysis was performed. The print in illustrations sub-theme is divided into the categories of labels, environmental print, visible speech, visible sound, and letters in isolation, while the print in the body of text sub-theme is divided into the categories of font changes and bold or unique fonts. The number of books collected within the categories is as follows: 32 books in labels, 40 books in the environmental print, 16 books in visible speech, 26 books in visible sound, 9 books in letters in isolation, 52 books in font changes, and 29 books in bold or unique fonts. While font changes and environmental print are found most frequently, the least mentioned is letters in isolation.
\end{abstract}

Keywords: Print referencing, Print salient features, Early print awareness, Children's picture books, Early childhood 
Filizlenen okuryazarlık ya da erken okuryazarlık olarak adlandırılan ve okuma yazma sürecinden öncesini kapsayan dönem, çocukların okuma yazmaya hazırlanmasından öte okuryazarlık becerilerinin temelinin oluşturulduğundan oldukça önemlidir (Ergül ve diğerleri, 2016; Işıtan ve Akoğlu, 2016; Justice ve Kaderavek, 2002). Bu dönem genel olarak kuluçka dönemi, ön okuryazarlık ve çocuğun çevresindeki bireylerin desteğiyle ses, harf, sözcük, metin, anlama ve ifade etme gibi becerilerin geliştirildiği bir süreçtir. Ayrıca bu süreç daha sonraki okuryazarlık becerilerini etkileyen erken beceri edinimi süreci olarak da ifade edilmektedir (Aşıc1, 2009; Çelenk, 2003; Nergis, 2008). Whitehurst ve Lonigan (1998) erken okuryazarlık gelişimini ilk olarak içeriden dışarıya ve daha sonra dışarıdan içeriye doğru birtakım davranış, bilgi, beceri ve tutum kazanma olarak tanımlamaktadır. Erken okuryazarlıkta gelişim gösterilen alanlar ise fonolojik farkındalık, yazı farkındalığı, dinlediğini anlama ve yazı yazma, alfabe ve harf bilgisi ve sözcük dağarcığıdır. Mevcut çalışma özelinde ele alınan yazı farkındalığı ise çocukların yazının işlevini, sözel dille ilişkisini ve şeklini anlamlandırmaları şeklinde ifade edilebilir. Ayrıca bu beceri, okul öncesi dönemdeki çocukların erken okuryazarlık gelişiminde önemli bir rol oynar (Zucker ve diğerleri, 2009).

Erken okuryazarlık becerileri geliştirilirken çocukların dergi, kitap, hikâye, masal ve şiir gibi dille ilgili çeşitli araçlarla etkileşimde bulunduğu (Gül, 2007) ve çevresinde bulunan yazılı sembollere ilgi göstererek yazıya yönelik gelişim gösterdiği (Aşıc1, 2009) görülmektedir. Ayrıca erken çocukluk döneminde çocuklar, çevresindeki kitap, gazete, yemek menüleri, trafik levhaları ve yiyecek ve içecek kutuları gibi araçlarla yazı bilgisi edinmektedir (Akyüz ve Doğan, 2017). Çocukların erken dönemlerde ilgi göstermeye başladığ1 konuşma dili ile yazı arasındaki farkı anlaması ise yazı farkındalığı geliştirdiğini göstermektedir (Bayraktar ve Temel, 2014). Clay (2007; 2013)'ın yazıya ilişkin kavramlar olarak tanımladığı birtakım alt beceriler mevcuttur. Bu alt beceriler kitabın ön ve arka kapağını göstermek, kitabın ismini söylemek, kitapta metnin okunduğunu ve metnin soldan sağa veya yukarıdan aşağıya doğru ilerlediğini bilmek, sözcük ve harfleri gösterebilmek, büyük ve küçük harfleri bilmek, sözcükte ve cümlede yer alan ilk ve son harfi göstermek, görseli ve metni tanımak ve temel noktalama işaretlerini bilmek şeklinde belirtilmektedir. Çocukların daha sonra iyi bir okuryazar olmaları (Hovland ve diğerleri, 2011) ve akademik becerilerini geliştirmek (DeretarlaGül ve Bal, 2006) için erken okuryazarlık bilgi ve becerilerini edinmesi önemlidir. Bu süreçte çocuklar, zenginleştirilmiş çevreye ve bakım veren kişilerin rehberliğine gereksinim duymaktadır (Türk, 2018). Böylece çocuklar zengin uyaranların olduğu ortamda sonraki okuryazarlıkları için sağlam bir temel oluşturmaktadır (McGinty ve Justice, 2009). Sonuç olarak, zenginleştirilmiş okuryazarlık ortamı ve bakım veren kişilerin desteği çocukların erken okuryazarlık becerilerinde iyi bir düzeyde olmalarına yardım etmektedir (FieldingBarnsley ve Purdie, 2003; Karaman ve Üstün, 2011; Levy ve diğerleri, 2005).

Çocukların yazı farkındalığı becerilerini geliştirmek için kullanılabilecek en güçlü araçlardan biri resimli çocuk kitaplarıdır (Ezell ve Justice, 2000). Bu kitapların sınıf ortamında sesli olarak okunması ile yazının ne anlam ifade ettiğinin yanı sıra yazının özelliklerine de dikkat çekilerek çocukların yazı bilgisi geliştirilebilir (Zucker ve diğerleri, 2009). Bunu yaparken "print referencing" olarak anılan ve mevcut çalışmada "yazı olarak niteleme" şeklinde adlandırılan bir teknikten yararlanılmaktadır. Bu, eğitimcilerin yazının biçimini, işlevini ve özelliklerini vurgulayarak çocukların yazı hakkında bilgisini ve farkındalığını arttırdıkları bir tekniktir (Justice ve Ezell, 2002, 2004; Justice ve diğerleri, 2009). Bu tekniğe başvurulduğunda kitaplar aracılığıyla görsellerin veya metnin kapsadığı "print salient features" olarak ifade edilen ve mevcut çalışmada "dikkati yazıya çeken özellikler" olarak adlandırılan birtakım özelliklerden yararlanılmaktadır. Dikkati yazıya çeken özellikler, metin ve görsel olarak ikiye ayrılmakta ve birtakım alt özellikleri kapsamaktadır. Zucker ve diğerleri (2009) metne ait özellikleri yazı biçimi değişikliği ve özel yazı karakteri kullanımı ve görsele ait özellikleri etiketler, çevresel yazı, konuşmanın gösterimi, sesin gösterimi ve harfin gösterimi olarak belirtmektedir. Metne ait özellikler altında ele alınan yazı biçimi değişikliği metinde kullanılan yazı tipinin rengi, boyutu veya yönü ile ilgili yapılan değişiklikleri kapsamaktadır. Özel yazı karakteri kullanımı ise metnin geneline göre bir kelimenin veya cümlenin farklı bir yazı karakteri kullanılarak veya italik, kalın veya altı çizili yazılması olarak tanımlanabilir. Görsele ait özellikler altında ele alınan etiketler şekillerin, diyagramların veya fotoğrafların bir yazı olarak nitelendirilmesidir. Çevresel yazı sıkça karşılaşılan nesnelerin üzerinde sembollerin, sözcüklerin veya harflerin yer almasıdır. Konuşmanın gösterimi karakterlere ait konuşmaların bir sözcük veya konuşma balonu ile gösterimi iken sesin gösterimi karakter veya nesnelerin 
çıkardığı seslerin yazılı olarak ifade edilmesidir. Harfin gösterimi ise, genellikle alfabe kitaplarında, harfin metinden ayrı olarak yazılmasıdır.

Justice ve Ezell (2004) yetişkinlerin paylaşımlı kitap okuma yöntemiyle çocukların yazıya ilgisinin arttırıldığını belirtmiştir. Anlamlı ve bağlamı olan hikâye kitabı okuma etkinlikleri ile çocukların üstdilsel ve okuryazarlık becerileri güçlendirilmektedir. Yapılan çalışmalar, yazı farkındalığını desteklemek için okuma etkinlikleri ile desteklenen risk altındaki çocukların becerilerinin olumlu yönde geliştiğini göstermiştir. Erken yazı farkındalığı becerileri desteklenen 30 okul öncesi çocuğu desteklenmeyenlere kıyasla daha fazla kazanıma sahip olmuştur (Justice ve Ezell, 2002). 106 okul öncesi çocukla yapılan başka bir çalışmada da öğretmenlerin kitap okuma etkinliklerinde "yazı olarak niteleme" stratejilerine başvurmasının çocukların erken okuryazarlık becerilerini geliştirdiği tespit edilmiştir (Justice ve diğerleri, 2009). Konuşma bozukluğu olan 4 yaşındaki 5 çocuk ile sınıfta yapılan bireyselleştirilmiş hikâye kitabı okuma etkinliklerinde ise çocukların yazı bilgisinin belirgin şekilde arttı̆̆ı ve tekrarlar ile öğrenmeye devam ettikleri görülmüştür (Lovelace ve Stewart, 2007).

Kitap okuma çocuk ve yetişkin arasında gerçekleşen etkileşimli bir deneyimdir. Bu deneyim çocukla yetişkinin okuma süreci boyunca etkin katılım gösterdiği ve görsel ve metin hakkında yaptıkları paylaşımları içeren bir süreci kapsar (Ezell ve Justice, 2005). Sınıfta veya evde sağlanan bu etkileşimler çocuğun erken okuryazarlık gelişiminde önemli bir rol oynamakta (Morrow ve Gambrell, 2004) ve özellikle yazı hakkında bilgisini arttırmaktadır (Sonnenschein ve Munsterman, 2002). Resimli çocuk kitapları okunurken dikkati yazıya çeken özellikler aracılığıyla yazı olarak niteleme stratejilerinden yararlanılabilir. Bu yüzden dikkati yazıya çeken özelliklere resimli çocuk kitaplarında nasıl yer verildiği merak uyandırmaktadır. Bu noktadan hareketle, mevcut çalışmanın amacı dikkati yazıya çeken özelliklerin resimli çocuk kitapları aracılığıyla örneklendirilmesi ve incelenen resimli çocuk kitaplarının bu özelliklerden hangisini kapsadığının belirlenmesidir. Mevcut çalışma bulguları ile erken okuryazarlık becerileri desteklenmek istendiğinde resimli çocuk kitaplarının barındırdıkları özelliklere göre seçim yapılabilmesi için birer öneri oluşturulacağı düşünülmektedir.

\section{Yöntem}

Bu çalışmada resimli çocuk kitaplarının dikkati yazıya çeken özelliklerini incelemek için nitel araştırma yöntemlerinden doküman analizi kullanılmıştır. Doküman analizi basılı veya elektronik olarak yer alan dokümanları inceleme ve değerlendirmeye yönelik sistematik bir süreçtir (Bowen, 2009). Araştırmada doküman olarak incelenen resimli çocuk kitaplarının dikkati yazıya çeken özelliklerine yönelik unsurlar betimlenerek ifade edilmiştir.

\section{Veri Toplama ve Analizi}

Çalışma örneklemini belirlemek için amaçlı örnekleme yöntemlerinden uygun örnekleme yöntemi seçilmiştir. Uygun örnekleme yoluyla toplanan resimli çocuk kitaplarının 3-6 yaş grubuna hitap etmesi, yazılı ve görsel unsurların yer alması, Türkçe yazılmış veya Türkçeye çevrilmiş olması ölçüt olarak belirlenmiştir. Bu kapsamda elde edilen 65 kitaptan 1 şiir kitabı, 2 sessiz kitap ile aynı özellikleri taşıyan ve aynı yayınevine ait olan 3 kitap elenmiş 59 resimli çocuk kitabı araştırma kapsamında değerlendirilmiştir. Verilerin, araştırmacıların iş birliği ile Zucker ve diğerleri (2009)'nin çalışmasında yer alan dikkati yazıya çeken özellikler çerçevesinde alt temalar ve kategoriler belirlenerek betimsel analizi yapılmıştır. İşbirlikli veri analizi, üzerinde anlaşmaya varılmış bir yorum üretmek için iki veya daha fazla araştırmacı arasında paylaşılan bir veri ile ilgili araştırmacıların ortak anlayış ve karşılıklı diyalog içerisinde yürüttüğü analiz sürecidir (Cornish ve diğerleri, 2013).

\section{Prosedür}

Mevcut araştırma üç aşamada gerçekleşmiştir. Birinci aşamada toplanılan verilerin analizine yönelik olarak "kitap kontrol formu" oluşturulmuştur. Formda kitaba yönelik künye bilgileri ve yazıya dikkat çeken özelliklere yönelik alt temalar ve kategorileri yer almaktadır. Belirlenen kitapların isimleri ve künye bilgileri bu forma listelenmiş ve her iki araştırmacı için kopya oluşturulmuş̧ur. İkinci aşamada, pilot çalışma yapılarak 
bir resimli çocuk kitabı belirlenmiş ve yazıya dikkat çeken özelliklere ait yedi kategoriye göre iki araştırmacı birlikte belirlenen kitabı incelemiştir. Bu inceleme sonrasında kategorilerin ortak anlam oluşturması için gerekli nitelikler karşılıklı diyalog ile netleştirilmiştir. Üçüncü aşamada ise kitapların hepsi bağımsız bir şekilde iki araştırmacı tarafından incelendikten sonra bir araya gelinerek bulgular üzerinde ortak bir görüşe gidilmiştir. Böylece formun son hali oluşturulmuştur. Oluşturulan ortak form aracılığıyla her kategoriden en az üç kitap seçilip kategoriye ait unsurlar çeşitlendirilmiş ve bulgular betimsel ve detaylı bir şekilde yazıya geçirilmiştir.

\section{Bulgular}

Resimli çocuk kitapları yazı farkındalığını geliştirmek için kullanılacağı zaman yararlanılacak bazı özellikler Zucker ve diğerleri (2009) tarafından dikkati yazıya çeken özellikler olarak tanımlanmış ve bu özellikler görseldeki yazı ve metindeki yazı şeklinde ikiye ayrılmıştır. Mevcut çalışmada, resimli çocuk kitapları bu özellikler çerçevesinde incelenmiş ve kitapların yazı farkındalığını desteklemek için nasıl birer araç olacakları tespit edilmiştir. Şekil 1'de gösterildiği gibi incelenen 59 resimli çocuk kitabı dikkati yazıya çeken özellikler teması çerçevesinde incelendiğinde kitaplarda yer alan özellikler görseldeki yazı ve metindeki yazı şeklinde iki alt tema altında toplanmıştır. Görseldeki yazı alt teması beş kategoriye ayrılmıştır. Bu kategoriler şunlardır: Etiketler, çevresel yazı, konuşmanın gösterimi, sesin gösterimi ve harfin gösterimi. Metindeki yazı alt teması ise iki kategoriye ayrılmıştır. Bu kategoriler şunlardır: Yazı biçimi değişikliği ve özel yazı tipi kullanımı. Bu bölümde her bir alt temaya ait kategoriler ayrı başlıklar halinde ele alınmıştır.

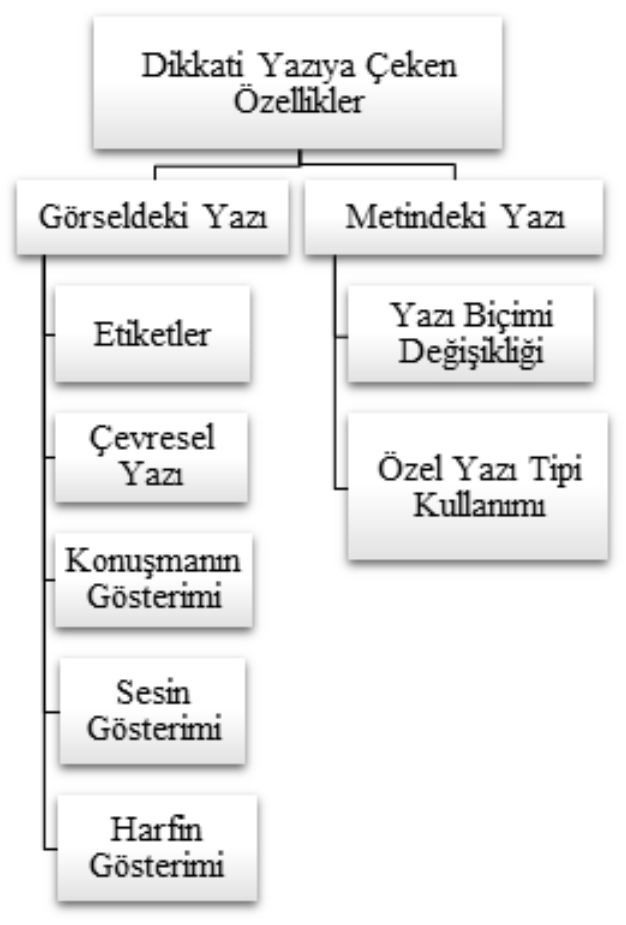

Şekil 1. Dikkati yazıya çeken özellikler temasına ait alt temalar ve kategoriler

Sahip oldukları özelliklere göre kategoriler altında toplanan kitaplar Tablo 1'deki gibidir. Kategorilere ait kitap sayıları şu şekildedir: Etiketler kategorisinde 32 tane kitap, çevresel yazı kategorisinde 40 tane kitap, konuşmanın gösterimi kategorisinde 16 tane kitap, sesin gösterimi kategorisinde 26 tane kitap, harfin gösterimi kategorisinde 9 tane kitap, yazı biçimi değişikliği kategorisinde 52 tane kitap, özel yazı tipi kullanımı kategorisinde 29 tane kitap. 
Söz Uçar, Yazı Dikkat Çeker: Resimli Çocuk Kitapları...

Tablo 1. Incelenen Kitaplarda Dikkati Yazıya Çeken Özelliklerin Dă̆ılımı

\begin{tabular}{|c|c|c|c|c|c|c|c|}
\hline \multirow[b]{2}{*}{ Kitabın İsmi } & \multicolumn{5}{|c|}{ Görseldeki Yazı } & \multicolumn{2}{|c|}{ Metindeki Yazı } \\
\hline & Etiketler & $\begin{array}{c}\text { Çevresel } \\
\text { Yazı } \\
\end{array}$ & $\begin{array}{c}\text { Konuşmanın } \\
\text { Gösterimi } \\
\end{array}$ & $\begin{array}{c}\text { Sesin } \\
\text { Gösterimi }\end{array}$ & $\begin{array}{l}\text { Harflerin } \\
\text { Gösterimi }\end{array}$ & $\begin{array}{l}\text { Yazı Biçimi } \\
\text { Değişikliği }\end{array}$ & $\begin{array}{c}\text { Özel Yazı Tipi } \\
\text { Kullanımı }\end{array}$ \\
\hline $\begin{array}{l}\text { Üzüm Sürünün En Küçük İneği } \\
\text { (Busch, 2019) }\end{array}$ & & + & & + & + & + & + \\
\hline Denemek (Yamada, 2020a) & + & & & & & & \\
\hline $\begin{array}{l}\text { Bir Fikirle Ne Yaparsın? (Yamada, } \\
\text { 2016) }\end{array}$ & + & & & & & + & \\
\hline $\begin{array}{l}\text { Çünkü Bir Öğretmenim Vardı } \\
\text { (Yamada, 2020b) }\end{array}$ & & + & & & & & \\
\hline Renklerin Kara Kitabı (Cotti, 2016) & & & & & + & + & \\
\hline $\begin{array}{l}\text { Bob ve Karga Sanatı (Deuchars, } \\
\text { 2019) }\end{array}$ & & + & + & & & + & + \\
\hline Boşluk (Llenas, 2019) & + & & & & & + & \\
\hline Zor Balık (Tarçalır-Erol, 2020) & & & & + & & + & + \\
\hline $\begin{array}{l}\text { Beril Kendi Resmini Yapıyor (Roca } \\
\text { ve Isern, 2019) }\end{array}$ & & + & & & & + & + \\
\hline Benim Müzem (Lewis, 2019) & & + & & & & + & + \\
\hline $\begin{array}{l}\text { Hiçbir Şey Yapmama Günü } \\
\text { (Alemagna, 2020) }\end{array}$ & & & & & & + & \\
\hline Yayazula (Donaldson, 2020a) & & & & + & & + & \\
\hline $\begin{array}{l}\text { Güzellik ve Sanat Nedir? (Brenifier, } \\
\text { 2013) }\end{array}$ & + & + & + & & + & + & + \\
\hline Tarhana Çorbası (Çınaroğlu, 2014) & & + & + & + & & + & \\
\hline $\begin{array}{l}\text { Kelime Koleksiyoncusu (Reynolds, } \\
\text { 2020d) }\end{array}$ & & + & + & & & + & + \\
\hline Minik Üzgün Kaktüs (Çelik, 2017) & + & + & + & & & + & \\
\hline Ateşim Çıktı (Çınaroğlu, 2019) & + & + & & + & & + & \\
\hline $\begin{array}{l}\text { Üç Kedi Bir Canavar (Şahinkanat, } \\
\text { 2020a) }\end{array}$ & & & & + & & + & \\
\hline Dönme Dolap (Kozikoğlu, 2020) & + & + & & & & + & \\
\hline Nefise Nine (en-Neccar, 2019) & & + & + & + & & + & + \\
\hline $\begin{array}{l}\text { Hiç Hata Yapmayan Kı (Pett ve } \\
\text { Rubinstein, 2020) }\end{array}$ & & + & + & + & & + & \\
\hline Zogi (Donaldson, 2020b) & & & & + & & + & \\
\hline Kitap Tamircisi Toprak (Berk, 2020) & + & + & & + & & + & \\
\hline $\begin{array}{l}\text { Ay'1 Kim Çaldı? (Stratton-Would, } \\
2020 \text { ) }\end{array}$ & + & + & & & & + & \\
\hline Nokta (Reynolds, 2020a) & + & + & & + & & + & \\
\hline mış gibi (Reynolds, 2020b) & + & + & & & & + & \\
\hline $\begin{array}{l}\text { Gökyüzünün Rengi (Reynolds, } \\
\text { 2020c) }\end{array}$ & & + & + & & & + & \\
\hline Renk Canavarı (Llenas, 2020) & + & & + & & & + & \\
\hline En Muhteşem Şey (Spiries, 2019) & + & + & + & + & & + & + \\
\hline Frederick (Lionni, 2020a) & & & + & & & + & \\
\hline Pezzettino (Lionni, 2020b) & + & & & & & + & + \\
\hline $\begin{array}{l}\text { Postacı Fare'nin Bir Günü (Dubuc, } \\
\text { 2020) }\end{array}$ & & + & + & + & & + & + \\
\hline $\begin{array}{l}\text { Anna'yı Gören Var M1? (Mattiangeli, } \\
\text { 2020) }\end{array}$ & + & + & & & & + & + \\
\hline Kızıl Ağaç (Shaw, 2020) & + & + & & & & + & + \\
\hline Kitabın Yolculuğu (Berk, 2019) & & + & & & & & \\
\hline Hiç Bitmeyen Şey (Docherty, 2019) & + & + & & & & + & \\
\hline $\begin{array}{l}\text { Möö La La Alışverişe Çıkan İnek } \\
\text { (Shaw, 2020) }\end{array}$ & + & + & + & + & & + & + \\
\hline
\end{tabular}




\begin{tabular}{|c|c|c|c|c|c|c|c|}
\hline $\begin{array}{l}\text { Kafası Karışık Bukalemun (Carle, } \\
\text { 2020) }\end{array}$ & & + & & & & + & + \\
\hline $\begin{array}{l}\text { Kütüphanedeki Aslan (Knudsen, } \\
\text { 2020) }\end{array}$ & & + & & + & + & + & \\
\hline $\begin{array}{l}\text { Bir Kedi Olsaydım (Sanchez- } \\
\text { Ibarzabal, 2019) }\end{array}$ & & + & & + & & + & + \\
\hline $\begin{array}{l}\text { Üç Kedi Bir Dilek (Şahinkanat, } \\
\text { 2020b) }\end{array}$ & & & & + & & + & \\
\hline $\begin{array}{l}\text { Mevsimlerin Renkleri Yeşil İlkbahar } \\
\text { Kitabım (Coucharriere, 2017) }\end{array}$ & + & + & & + & & + & + \\
\hline $\begin{array}{l}\text { Yaprak Dedikleri Var Ya... (Purdie- } \\
\text { Salas, 2017) }\end{array}$ & + & + & & & & & \\
\hline Bir Renk (Yemen, 2020) & & + & & & & + & + \\
\hline Mutlu Suaygırı (Edwards, 2020) & + & & & + & & + & + \\
\hline Köpekler Bale Yapmaz (Kemp, 2020) & & + & & & & + & + \\
\hline $\begin{array}{l}\text { Carl ve Yaşamın Anlamı (Freedman, } \\
\text { 2019) }\end{array}$ & & & & + & & + & + \\
\hline Kaşal (Maclear, 2018) & + & + & & & & + & + \\
\hline $\begin{array}{l}\text { Bu Kitabın Ortasında Duvar Var } \\
\text { (Agee, 2018) }\end{array}$ & + & & + & + & & + & + \\
\hline $\begin{array}{l}\text { Başka Bir Yerde Yaşasaydım } \\
\text { (Orbeck-Nilssen, 2017) } \\
\end{array}$ & & + & & & & & \\
\hline Çilli (Nuñez, 2014) & + & + & & + & & + & + \\
\hline Salih Peygamber (Santur, 2018) & & & & + & + & + & + \\
\hline Nasıl Başlar? (Tavano, 2017) & + & + & & + & + & + & + \\
\hline $\begin{array}{l}\text { Dünyanın En Güzel Kalbi (Ünal, } \\
\text { 2016) }\end{array}$ & + & + & & + & & + & + \\
\hline Sessizlik (APA, 2018) & + & & & & & & \\
\hline Yüzyüz (Lionni, 2017) & + & & & & & + & \\
\hline Ben Rembrandt (Sonmaz, 2012) & + & + & & & & + & \\
\hline Ben Kitap (Sonmaz, 2021) & + & + & + & & + & + & + \\
\hline Ben Miro (Şengül, 2021) & + & + & + & & + & + & + \\
\hline $\begin{array}{l}\text { Guguklu Saatin Küçük Kuşu (Oral, } \\
\text { 2021) }\end{array}$ & + & & & + & & & \\
\hline
\end{tabular}

\section{Görseldeki Yazı}

\section{Etiketler}

Kitapların görselleri incelendiğinde 32 tane kitabın etiketler kategorisi altında toplandığı görülmüştür. Bu kategori kitaplarda çeşitli diyagramları, figürleri, tabloları veya fotoğrafları kapsamaktadır. Etiketler kategorisine ait örneklere aşağıda yer verilmiştir.

"Boşluk" (Llenas, 2019) kitabında kahramanın eksikliğini hissettikleri ve kitap boyunca tanımlamaya çalıştıkları karın bölgesinde yer alan bir boşlukla görselleştirilmiştir. Kitabın ismiyle de aynı olan bu sembol ile yazar okura anlatmak istediklerini yalnızca görsel kullanarak aktarmaktadır.

"Ateşim Çıktı" (Çınaroğlu, 2019) kitabında hasta olan çocukların burunlarının ve yanaklarının kırmızı, hastalığın şiddetinin içinde deniz canlılarının yaşadığı sümükten bir denizin veya baş ağrısının Kızılderililerin müzik çalıp oynadıkları bir sahnenin görselleri birer metin gibi kullanılarak tüm detayına kadar hastalık okura aktarılmaktadır.

"Ay'ı Kim Çaldı?" (Stratton-Would, 2020) kitabında kahramanımız Ay'ı çaldığını düşündüğü hayvanları bu düşüncesini daha dile getirmeden Ay'ı sırtında, ağzında veya elinde bir yerlere götürürken hayal etmiş ve bu düşünceler metinle değil bu görsellerle okura anlatılmıştır.

\section{Çevresel Yazı}


Mevcut çalışmada incelenen kitaplardan 40 tanesinin çevresel yazı kategorisinin altında yer aldığı tespit edilmiştir. Bu kategoride yer alan kitaplarda çocukların sıklıkla karşılaşabilecekleri nesnelerin üzerinde etiketlerin, sözcüklerin veya harflerin yer aldığı ve bu etiketlerin nesneyi genellikle adlandırmak için kullanıldığı görülmüştür. Çevresel yazıya bazı kitaplarda trafik levhaları ve işaretleri, çeşitli haritalar, kitap isimleri veya bazı mekanlara ait tabelalar kullanılarak da yer verilmiştir. Çevresel yazı kategorisine ait örneklere aşağıda yer verilmiştir.

“Üzüm Sürünün En Küçük İneği” (Busch, 2019) kitabında kahramanın film izlemek için tırmandığ1 çitlerin hemen karşısındaki sinemanın yanındaki büyük bir afişin üzerinde "Moon Jump" şeklinde gösterimdeki filmin adı yer almaktadır. Ayrıca sinema binasının hemen üzerindeki büyük bir mısır kutusu üzerinde de "MISIR" yazmaktadır.

"Bob ve Gaga Sanatı" (Deuchars, 2019) kitabında Bob'un problemini çözmek için araştırma yaparken gittiği mekanların üzerindeki tabelalarda "SPOR SALONU", "RESTORAN","MODACI" veya "SANAT GALERISİ” yazdığı görülmektedir.

“Tarhana Çorbası" (Çınaroğlu, 2014) kitabında çorbanın nasıl içilirse daha iyi olacağının anlatıldığı sayfada yer alan peynir kutusunun üzerinde "BEYAZ PEYNIR" yazmaktadır.

“Nefise Nine" (en-Neccar, 2019) kitabında Nefise Nine'nin boya tüplerinin veya banyodaki kutuların üzerinde etiketleri ve torunuyla birlikte gittikleri hurda dükkânın ve o sokakta yer alan diğer dükkanların üzerindeki tabelalarda isimleri yer almaktadır.

\section{Konuşmanın Gösterimi}

Çalışma kapsamında incelenen resimli çocuk kitapları arasından 16 kitapta konuşmanın gösterildiği belirlenmiştir. Konuşmanın gösterimi, kitaptaki karakter veya karakterlerin yakınında konuştuğunun gösterilmesi ya da konuşma balonunun yer almasıdır. Bu kategori konuşmanın yazı halinde gösterilmesini amaçlamaktadır. Konuşmanın gösterimi kategorisine ait örneklere aşağıda yer verilmiştir.

"Ben Miró" (Şengül, 2021) kitabında Giocometti ve Prats karakterlerinin Miró ile ilgili görüşleri konuşma balonun içinde yer almış ve konuşmalar bu şekilde metinleştirilmiştir. Kitapta geçen konuşma balonu doğrudan konuşmanın gösterimi kategorisi özelliği belirteci olmuştur.

"Gökyüzünün Rengi" (Reynolds, 2020c) kitabındaki baş karakter olan Marisol'un sayfada tek başına yer alması ve birinci tekil şahıs anlatıcısı şeklindeki konuşması yine konuşmanın gösterimi kategorisine bir örnek oluşturmaktadır.

“Möö La La Alışverişe Çıkan İnek” (Shaw, 2020) kitabında baş karakter Möö La La ve boğanın sayfada karaktere ait fotoğraf ile tırnak işareti içerisinde verilmiş konuşmasının bir anlatıcı ifadesi yer almadan (dedi, söyledi gibi) metinleştirilmesi kitapta konuşmanın gösterimini sağlamaktadır.

\section{Sesin Gösterimi}

İncelenen resimli çocuk kitaplarından 26 tanesinde sesin gösterimine ulaşılmıştır. Resimli çocuk kitaplarında sesin gösterilmesi kitapta yer alan karakter veya nesnelere ait seslerin yazı içinde yer almasını kapsamaktadır. Bu kategori ile sesin yazı olarak ifade edebileceğini göstermek amaçlanmaktadır. Sesin gösterimine kedinin miyavlamasının "mırrr", kapıya vurma sesinin "tak tak" veya akan suyun "şırr" sesi olarak metnin içerisinde gösterilmesi örnek oluşturabilir. Sesin gösterimi kategorisine ait örneklere aşağıda yer verilmiştir.

"Nokta" (Reynold, 2020a) kitabında yer alan karakterlerden öğretmen ve Vashti'nin "hmmmm" seslerinin ve yine öğretmenin "Aaa" şaşırma sesinin metinde yazı halinde yer alması sesin gösterimi kategorisi içerisinde değerlendirilmektedir.

“Üç Kedi bir Canavar" (Şahinkanat, 2020a) kitabında rüzgâr sesinin "uuuu” dalların çatırdama sesinin çat çat, inleme sesinin "Viiik", uluma sesinin "AAUUU! AAUU!", homurdanma sesinin "HIIIM HUUUM HUUUM!", kalp atış sesinin "küt küt... küt küt, korkma sesi olduğu belirtilmese de korktuklarını anladığımız 
“Hiii!" sesinin metin içerisinde yazı halinde yer alması sesin gösteriminin yer aldığını ifade etmektedir.

“Bu Kitabın Ortasında Duvar Var" (Agee, 2018) kitabındaki dev karakterinin gülme sesinin "Ha ha ha ha!" olarak metnin içerisinde yazı halinde yer alması sesin gösterimi kategorisinin kitapta bulunmasını ifade etmektedir.

\section{Harfin Gösterimi}

Harflerin ayrı olarak metinde ya da görselde yer almasıdır. Kelime içerisindeki farklılaşmış bir harf de bu kategori kapsamına girmektedir. Harfin gösterimi kategorisi ile kitap içerisinde harfin kendisinin fark edilmesi amaçlanmaktadır. İncelenen 59 resimli çocuk kitabından 9 tanesinde bu kategoriye ait unsurlar yer almaktadır. Harfin gösterimi kategorisine ait örneklere aşağıda yer verilmiştir.

"Ben Kitap" (Sonmaz, 2021) kitabının dokuzuncu sayfasında farklı alfabelere ait harflerin yer aldığı görülmektedir. Bu durum harfin gösterimi kategorisinin kitaptaki göstergesi olarak değerlendirilmektedir.

“Kütüphanedeki Aslan" (Knudsen, 2020) kitabında ilk sayfadaki ilk sözcük olan "Günlerden" kelimesindeki " $G$ " harfinin diğer harflerinden farklılaştırılarak yazılması ve kitabın ilerleyen sayfalarındaki ilk kelimedeki ilk harflerin diğer harflerden farklı ve belirgin yazılması kitap içinde harf gösterimi kategorisine ait bir unsur olarak değerlendirilmektedir.

“Nasıl Başlar?" (Tavano, 2017) kitabının 5. ve 6. sayfalarında alfabenin ilk ve son harflerine atıf yaparak " $\mathrm{A}$ " ve "Z" harflerinin yer alması kitapta harfin gösterimi için örnek oluşturmaktadır.

\section{Metindeki Yazı}

Yazı Biçimi Değişikliği. İncelenen 59 resimli çocuk kitabının 52 tanesinde yazı biçiminde değişiklik yapıldığı görülmektedir. Metindeki yazı teması altında yer alan yazı biçimi değişikliği kategorisine incelenen kitapların birçoğunun dahil edildiği ve bu özelliğin yazı farkındalığını desteklemek amacıyla çoğunlukla yararlanılacak bir özellik olduğu söylenebilir. Kitaplarda yazı değişikliği yapılırken bazı metinlerin boyutu, rengi veya konumu kitapta yer alan diğer metinlere göre farklılaştırılmıştır. Bu şekilde amaçlı veya amaç dışında metinlerin bazılarına dikkat çekilmeye çalışılmıştır. Yazı biçimi değişikliği kategorisine ait örneklere aşağıda yer verilmiştir.

“Bir Fikirle Ne Yaparsın?" (Yamada, 2016) kitabında “BENIM" sözcüğünün diğer sözcüklerden farklı olarak tamamen büyük harflerle yazıldığı görülmektedir.

"Beril Kendi Resmini Yapıyor" (Roca ve Isern, 2019) kitabında yer alan başlıkların soldan sağa ancak kıvrımlı, yukarıdan aşağıya veya aşağıdan yukarıya doğru ve bazı görsellerin isimleri diğer metinden ayrılarak hemen görselin altına yazılmıştır.

"Kelime Koleksiyoncusu" (Reynolds, 2020d) kitabında çoğu sözcük kâğıt parçaları üzerinde, tamamen büyük harflerle veya farklı yönlere doğru yazılmış bir şekilde yer almaktadır.

\section{Özel Yazı Tipi Kullanımı}

29 kitabın metinlerinin bir kısmının kalın, italik veya altı çizili yazıldığı tespit edilmiştir. Bazı kitaplarda da çoğunlukla kullanılan fontun dışında metnin bazı kısımlarının farklı bir yazı tipi kullanılarak yazıldığı görülmüştür. Özel yazı tipi kullanımı kategorisine ait örneklere aşağıda yer verilmiştir.

"Zor Balık" (Tarçalır-Erol, 2020) kitabında “Benekli Çöpçüüü!", “Tak tak!” veya "güçlü” gibi dikkat çekilmek istenen sözcüklerin veya söz öbeklerinin diğer sözcüklerden farklı olarak kalın yazıldığı görülmektedir.

“En Muhteşem Şey” (Spiries, 2019) kitabında dikkat çekilmek istenen “AHHHH!", “MUHTEŞEM” veya "BEYNI" gibi sözcükler cümle içinde veya şekil içinde metnin geri kalanından farklı bir yazı tipinde yazılmıştır. 
"Postacı Fare'nin Bir Günü" (Dubuc, 2020) kitabında yer alan tabelaların, etiketlerin veya seslerin metnin geri kalanından farklı bir yazı tipinde ve bu sözcüklerin genellikle kalın, büyük harflerle veya farklı bir renkte yazıldığı tespit edilmiştir.

\section{Sonuç ve Tartışma}

Mevcut çalı̧̧ma, resimli çocuk kitaplarındaki dikkati yazıya çeken özelliklerin belirlenmesi ve örneklendirilmesi amacıyla yapılmıştır. İncelenen 59 kitapta yer alan dikkati yazıya çeken özellikler görseldeki yazı ve metindeki yazı alt temalarına ait toplam yedi kategoriye göre incelenmiştir. İlk alt tema etiketler, çevresel yazı, konuşmanın gösterimi, sesin gösterimi ve harfin gösterimi kategorilerinden oluşurken, ikinci alt temaya ait kategoriler yazı biçimi değişikliği ve özel yazı tipi kullanımıdır. Bu bölümde kitaplarda yer alan özelliklere ilişkin bulgular, alan yazında yer alan çalışmalar ışığında tartışılacaktır.

İncelenen kitaplarda dikkati yazıya çeken özelliklerin birden fazlasına yer verildiği ve kitaplardan altı tanesinin yalnızca bir özelliği barındırdığı görülmüştür. Yapılan çalışmalarda, yazı olarak niteleme stratejisinin sesli kitap okuma çalışmaları sırasında yaygın bir şekilde kullanımının ve dikkati yazıya çeken özelliklerden bu okumalar sırasında yararlanılmasının çocukların yazıya ilişkin bilgi ve farkındalığını arttırdığı görülmüştür (Alatalo ve Westlund, 2019; Sanderson, 2017). Bu strateji için dikkati yazıya çeken özellikleri barındıran kitapların kullanılması anlamlı ve olumlu sonuçlar alınmasını sağlamaktadır. Ayrıca okul öncesi sınıflarında güne çoğunlukla kitap okuyarak başlandığı (Zucker ve diğerleri, 2009) ve sınıfta öğretmenin okumaları yaparken bu stratejiyi kullanmasının yazıyla ilişki kuran çocuklarda erken okuryazarlığa ilgiyi ve dil gelişimini desteklediği görülmektedir (Lovelace ve Stewart, 2007; Piasta ve diğerleri, 2021; Wright, 2019).

Kitapların 52 tanesinin yazı biçimi değişikliği ve 29 tanesinin özel yazı tipi kullanımı özelliklerini barındırması resimli çocuk kitaplarındaki metin aracılığıyla yazı farkındalığına yönelik daha fazla destek sağlanabileceğini düşündürmektedir. Bunun yanı sıra görseldeki yazı alt temasına ait çevresel yazı, etiketler ve sesin gösterimi özelliklerine de birçok kitapta yer verilmiştir. Buradan hareketle, erken yazı farkındalığını ve yazıya yönelik bilgiyi geliştirmek için resimli çocuk kitaplarındaki metin kadar görsellerin de kullanılabileceği sonucuna ulaşılabilir. Özellikle dezavantajlı çocuklarla yapılan çalışmalarda, evde veya sinıfta sesli kitap okuma etkinliklerinde metnin veya görselin sahip olduğu bu özelliklerden yararlanılarak kurulan etkileşimin erken okuryazarlık becerilerini desteklediği görülmüştür (Chang ve diğerleri, 2016; Rao ve diğerleri, 2016). Ayrıca Neumann ve diğerleri (2015) yaptıkları çalışmada okul öncesi çocukların çevrelerinde bulunan kelime, logo veya resimden ziyade kitapta yer alan ve görseldeki yazı olarak belirttiğimiz çevresel yazı özelliğine daha fazla dikkat ettiğini tespit etmiştir. Dikkati yazıya çeken özellikleri barındıran kitaplar ile yapılacak çalışmalar aracılığıyla çocukların erken yazı farkındalığı becerilerinin etkili bir şekilde desteklenebilir.

Sonuç olarak hem evde hem de sınıfta yetişkin desteği ile yapılacak sesli kitap okuma çalışmaları sırasında yazı olarak niteleme stratejisinden yararlanılarak çocukların erken yazı farkındalığının ve bilgisinin etkili bir şekilde destekleneceği söylenebilir. Bu etkinlikler sırasında yazı olarak niteleme stratejisinde yalnızca metnin değil görsellerin de birer araç olarak kullanıldığı ve resimli çocuk kitaplarının bu iki araca da ait özelliklerin birçoğunu barındırdığı görülmüştür. Bu stratejinin etkinliklerde kullanımının yaygınlaştırılması ve dikkati yazıya çeken özellikleri barındıran resimli çocuk kitaplarının niteliğinin arttırılması için daha fazla araştırmaya ihtiyaç duyulmaktadır.

\section{Yazarların Beyanı}

Araştırmacıların katkı oranı beyanı: Bu çalışmanın tümü doküman incelemesi yapılarak yazarlar tarafından gerçekleştirilmiştir.

Etik Kurul Kararı: Doküman incelemesine yönelik bir çalışma olduğu için etik kurul kararı gerekmemektedir.

Çatışma Beyanı: Araştırmada, yazarların kendi içinde ve diğer kişi/kurum/kuruluşlarla herhangi bir çıkar çatışması söz konusu değildir. 
Elif KURAL \& Fatma Merve ŞİMŞEK

Destek ve Teşekkür: Çalışmada herhangi bir kurum ya da kuruluştan destek alınmamıştır.

\section{Kaynaklar}

Akyüz, E., \& Doğan, Ö. (2017). Ev okuryazarlık ortamı: Tanımları, boyutları ve kendiliğinden ortaya çıkan okuryazarlık becerilerinin gelişimindeki rolü. Hacettepe Üniversitesi Sağlık Bilimleri Fakültesi Dergisi, 4(3), 38-57.

Alatalo, T., \& Westlund, B. (2019). Preschool teachers' perceptions about read-alouds as a means to support children's early literacy and language development. Journal of Early Childhood Literacy, 1468798419852136.

Aşıcı, M. (2009). Kişisel ve sosyal bir değer olarak okuryazarlık. Değerler Eğitimi Dergisi, 7(17), 9-26.

Bayraktar, V., \& Temel, F. (2014). Okuma-Yazmaya Hazırlık Eğitim Programı'nın çocukların okuma yazma becerilerine etkisi. Hacettepe Üniversitesi Eğitim Fakültesi Dergisi, 29(3), 08-22.

Bowen, G. A. (2009), Document analysis as a qualitative research method. Qualitative Research Journal, 9 (2), 27-40. https://doi.org/10.3316/QRJ0902027

Chang, C. J., Luo, Y. H., \& Wu, R. (2016). Origins of print concepts at home: Print referencing during joint book-reading interactions in Taiwanese mothers and children. Early Education and Development, 27(1), 54-73.

Clay, M. M. (2007). Concepts About Print. What Have Children Learn About The Way We Print Language? Heinemann.

Clay, M. M. (2013). An Observation Survey of Early Literacy Achievement (3. Bask1). Portsmouth, NH: Heinemann.

Cornish, F., Gillespie, A., \& Zittoun, T. (2013). Collaborative Analysis of Qualitative Data. The Sage Handbook of Qualitative Data Analysis.

Çelenk, S. (2003). İlkokuma-yazma öğretiminde kuluçka dönemi. Ankara Üniversitesi Eğitim Bilimleri Fakültesi Dergisi, 36(1-2), 75-80.

Deretarla-Gül, E., \& Bal, B. (2006). Anasınıfı öğretmenlerinin okuma yazmaya hazırlık çalışmalarına ilişkin bakış açıları, sınıf içi kullanılan materyal ve etkinlikler ile çocukların okuma yazmaya ilgilerinin incelenmesi. Çocuk Gelişimi ve Eğitimi Dergisi, 1(2), 33-51.

Ergül, C., Sarıca, A. D., \& Akoğlu, G. (2016). Etkileşimli kitap okuma: Dil ve erken okuryazarlık becerilerinin geliştirilmesinde etkili bir yöntem. Ankara Üniversitesi Eğitim Bilimleri Fakültesi Özel Eğitim Dergisi, 17(2), 193-204.

Ezell, H. K., \& Justice, L. M. (2000). Increasing the print focus of adult-child shared book reading through observational learning. American Journal of Speech-Language Pathology, 9(1), 36. doi:10.1044/10580360.0901 .36

Ezell, H. K., \& Justice, L. M. (2005) Shared Storybook Reading: Building Young Children's Language and Emergent Literacy Skills. Paul H. Brookes Publishing Co.

Fielding-Barnsley, R., \& Purdie, N. (2003). Early intervention in the home for children at risk of reading failure. Support for Learning: British Journal of Learning Support, 18(2), 77-82.

Gül, G. (2007). Okuryazarlık sürecinde aile katılımının rolü. Ankara Üniversitesi Eğitim Bilimleri Fakültesi Dergisi, 8(1), 17-30.

Hovland, M. R., Gapp, S. G., \& Theis, B. L. (2011). Look: Examining the concept of learning to look at print. Reading Improvement, 48(3), 128-137.

Işıtan, S., \& Akoğlu, G. (2016). Yazı farkındalığı becerilerinin resimli çocuk kitabı aracılığıyla 
Söz Uçar, Yazı Dikkat Çeker: Resimli Çocuk Kitapları...

değerlendirilmesi: güvenirlik ve geçerlik çalışması. Turkish Studies, 11(3), 1333-1352.

Justice, L. M., \& Ezell, H. K. (2002). Use of storybook reading to increase print awareness in at-risk children. American Journal of Speech-Language Pathology, 11(1), 17. doi:10.1044/1058-0360(2002/003)

Justice, L. M., \& Ezell, H. K. (2004). Print referencing. Language Speech and Hearing Services in Schools, 35(2), 185. doi:10.1044/0161-1461(2004/018)

Justice L. M., \& Kaderavek, J. N. (2002). Using shared storybook reading to promote emergent literacy. Teaching Exceptional Children, 34(4), 8-13.

Justice, L. M., Kaderavek, J. N., Fan, X., Sofka, A., \& Hunt, A. (2009). Accelerating preschoolers' early literacy development through classroom-based teacher-child storybook reading and explicit print referencing. Language Speech and Hearing Services in Schools, 40(1), 67. doi:10.1044/0161-1461(2008/07-0098)

Karaman, G., \& Üstün, E. (2011). Anasınıfına devam eden çocukların fonolojik duyarlılıklarının bazı değişkenlere göre incelenmesi. Hacettepe Üniversitesi Eğitim Fakültesi Dergisi, 40, 267-278.

Levy, B. A., Gong, Z., Hessels, S., Evans, M. A., \& Jared, D. (2005). Understanding print: Early reading development and the contributions of home literacy experiences. Journal of Experimental Child Psychology, 93, 63-93.

Lovelace, S., \& Stewart, S. R. (2007). Increasing print awareness in preschoolers with language impairment using non-evocative print referencing. Language Speech and Hearing Services in Schools, 38(1), 16. doi:10.1044/0161-1461(2007/003)

McGinty, A. S. \& Justice, L. M. (2009). Predictors of print knowledge in children with specific language impairment: Experiential and developmental factors. Journal of Speech, Language, and Hearing Research, 52, 81-97.

Morrow, L. M., \& Gambrell, L. B. (2004). Using Children's Literature in Preschool. Comprehending and Enjoying Books. International Reading Association.

Nergis, A. (2008). İlköğretim birinci sınıf öğrencilerinin ön okuryazarlık davranışları ile annelerinin okuryazarlığa olan ilgisi arasındaki ilişki. [Yüksek lisans tezi]. Marmara Üniversitesi.

Neumann, M. M., Summerfield, K., \& Neumann, D. L. (2015). Visual attention to print-salient and picturesalient environmental print in young children. Reading and Writing, 28(4), 423-437.

Piasta, S. B., Logan, J. A., Thomas, L. J., Zettler-Greeley, C. M., Bailet, L. L., \& Lewis, K. (2021). Implementation of a small-group emergent literacy intervention by preschool teachers and community aides. Early Childhood Research Quarterly, 54, 31-43.

Rao, S. M., Newlin-Haus, E., \& Ehrhardt, K. (2016). Repeated interactive read-aloud: Enhancing literacy using story props. Childhood Education, 92(3), 226-235.

Sanderson, C. A. (2017). The use of print referencing techniques through preschoolers' play-based creative writing experiences: The impact on oral language development, print awareness, and literacy abilities with children diagnosed with language disorder. [Doktora tezi, Güney Karolina Üniversitesi].

Sonnenschein, S., \& Munsterman, K. (2002). The influence of home-based reading interactions on 5-year-olds' reading motivations and early literacy development. Early Childhood Research Quarterly, 17(3), 318337. doi.org/10.1016/S0885-2006(02)00167-9

Türk, Z. (2018). Çocuk Evleri Sitesi'nde kalan çocukların yazı farkındalığı becerilerinin değerlendirilmesi. [Yüksek lisans tezi]. Ankara Üniversitesi.

Whitehurst, G. J. \& Lonigan, C. J. (1998). Child development and emergent literacy. Child Development, 69(3), 848-872.

Wright, T. S. (2019). Reading to learn from the start: The power of interactive read-alouds. American 
Educator, 42(4), 4.

Zucker, T. A., Ward, A. E., \& Justice, L. M. (2009). Print referencing during read-alouds: A technique for increasing emergent readers' print knowledge. The Reading Teacher, 63(1), 62-72.

\section{Resimli Çocuk Kitaplarına Ait Kaynaklar}

Agee, J. (2018). Bu Kitabın Ortasinda Duvar Var. Domingo Yayınevi.

Alemagna, B. (2020). Hiçbir Şey Yapmama Günü. Aylak Kitap.

APA. (2018). Sessizlik. Okuyan Koala.

Berk, E. (2019). Kitabın Yolculuğu. Yapı Kredi Yayınları.

Berk, E. (2020). Kitap Tamircisi Toprak. Final Kültür Sanat Yayınları.

Brenifier, O. (2013). Güzellik ve Sanat Nedir?. Filozof Çocuk.

Busch, M. (2019). Üzüm Sürünün En Küçük İneği. Beyaz Balina.

Carle, E. (2020). Kafası Karışık Bukalemun. Kuraldışı Çocuk.

Cotti, M. (2016). Renklerin Kara Kitabı. EDAM.

Coucharriere, S. (2017). Mevsimlerin Renkleri Yeşil İlkbahar Kitabım. 1001 Çiçek Kitaplar.

Çelik, G. M. (2017). Minik Üzgün Kaktüs. Kumdan Kale.

Çınaroğlu, A. (2014). Tarhana Çorbası. Kırmızı Kedi.

Çınaroğlu, A. (2019). Ateşim Çıktı. Yapı Kredi Yayınları.

Deuchars, M. (2019). Bob ve Gaga Sanatı. FOM Kitap.

Docherty, H. (2019). Hiç Bitmeyen Şey. Pearson.

Donaldson, J. (2020a). Yayazula. Türkiye İş Bankası.

Donaldson, J. (2020b). Zogi. Türkiye İş Bankası.

Dubuc, M. (2020). Postacı Fare'nin Bir Günü. RedHouse kidz.

Edwards, R. (2020). Mutlu Suaygırı. Türkiye İş Bankası.

en-Neccar, T. (2019). Nefise Nine. Yapı Kredi Yayınları.

Freedman, D. (2019). Carl ve Yaşamın Anlamı. Kuraldışı Çocuk.

Kemp, A. (2020). Köpekler Bale Yapmaz. Pearson.

Knudsen, M. (2020). Kütüphanedeki Aslan. Uçanbalık.

Kozikoğlu, T. (2020). Dönme Dolap. Doğan Egmont.

Lewis, E. (2019). Benim Müzem. RedHouse Kidz.

Lionni, L. (2017). Yüzyüz. Elma Çocuk.

Lionni, L. (2020a). Frederick. Elma Çocuk.

Lionni, L. (2020b). Pezzettino. Elma Çocuk.

Llenas, A. (2019). Boşluk. Nesin Yayınevi.

Llenas, A. (2020). Renk Canavarı. Nesin Yayınevi.

Maclear, K. (2018). Kaşal. Hep Kitap. 
Mattiangeli, S. (2020). Anna'yı Gören Var Mı?. Çınar Yayınları.

Nuñez, M. (2014). Çilli. RedHouse kidz.

Oral, F. (2021). Guguklu Saatin Küçük Kuşu. Yapı Kredi Yayınları.

Orbeck-Nilssen, C. (2017). Başka Bir Yerde Yaşasaydım. ABM Yayınevi.

Pett, M. ve Rubinstein, G. (2020). Hiç Hata Yapmayan Kız. 1001 Çiçek Kitaplar.

Purdie-Salas, L. (2017). Yaprak Dedikleri Var Ya... Tübitak.

Reynolds, P. H. (2020a). Nokta. Altın Kitaplar.

Reynolds, P. H. (2020b). mış gibi. Altın Kitaplar.

Reynolds, P. H. (2020c). Gökyüzünün Rengi. Altın Kitaplar.

Reynolds, P. H. (2020d). Kelime Koleksiyoncusu. Altın Kitaplar.

Roca, N. ve Isern, C. (2019). Beril Kendi Resmini Yapıyor. Tübitak.

Sanchez-Ibarzabal, P. (2019). Bir Kedi Olsaydım. Nesin Yayınevi.

Santur, E. (2018). Salih Peygamber. Multibem.

Shaw, S. (2020). Möö La La Alışverişe Çıkan İnek. Pearson.

Sonmaz, S. (2012). Ben Rembrandt. SSM Yayınevi.

Sonmaz, S. (2021). Ben Kitap. SSM Yayınevi.

Spiries, A. (2019). En Muhteşem Şey. Tübitak.

Stratton-Would, H. (2020). Ay'ı Kim Çaldı?. Yapı Kredi Yayınları.

Şahinkanat, S. (2020a). Üç Kedi Bir Canavar. Yapı Kredi Yayınları.

Şahinkanat, S. (2020b). Üç Kedi Bir Dilek. Yapı Kredi Yayınları.

Şengül, S. (2021). Ben Miro. SSM Yayınevi.

Tan, S. (2020). Kızıl A ̆̆aç. İthaki Çocuk.

Tarçalır-Erol, B. (2020). Zor Balık. RedHouse Kidz.

Tavano, S. (2017). Nasıl Başlar?. Yapı Kredi Yayınları.

Ünal, H. (2016). Dünyanın En Güzel Kalbi. Multibem.

Yamada, K. (2016). Bir Fikirle Ne Yaparsın?. Nar Çocuk.

Yamada, K. (2020a). Denemek. Nar Çocuk.

Yamada, K. (2020b). Çünkü Bir Öğretmenim Vardı. Nar Çocuk.

Yemen, G. (2020). Bir Renk. Masal Perest. 


\section{EXTENDED ABSTRACT}

\section{Purpose}

Print salient features were exemplified through children's picture books and their features were determined. According to the findings, the other purpose of the present study was to create a proposal to select children's picture books according to these features in order to support early literacy skills.

\section{Method}

In the present study, document analysis was conducted to determine the print salient features in children's picture books. With appropriate sampling, 59 books were determined based on the criteria of addressing the 3-6 age group, including written and visual elements, and being written in or translated into Turkish. Descriptive analysis was performed. First of all, the researchers independently determined the books' features and then these features were finalized in a common table that they created after coming together.

\section{Findings}

The findings were obtained by determining the features of the books that were included in the subthemes of the theme of the features that attract attention to print: print in illustrations and print in the body of text. The print in illustrations sub-theme is divided into the categories of labels, environmental print, visible speech, visible sound, and letters in isolation, while the print in the body of text sub-theme is divided into the categories of font changes and bold or unique fonts. The number of books collected within the categories according to the features that attract attention to print is as follows: 32 books in the category of labels, 40 books in the environmental print category, 16 books in the visible speech category, 26 books in the visible sound category, 9 books in the category of letters in isolation, 52 books in the font changes category, and 29 books in the bold or unique fonts category. As a result, while the font changes and environmental print features are found most frequently in the books examined, the least mentioned feature is letters in isolation. Examples of the categories are as follows:

In the book "Boşluk" (Llenas, 2019), the protagonist is visualized with a void in the abdomen that they feel lacking and try to define it throughout the book. With this symbol, which is the same as the name of the book, the author conveys what he wants to tell the reader by using only visuals.

In the book "Bob ve Gaga Sanatı" (Deuchars, 2019), it is seen that the signs on the places that Bob went to while doing research to solve his problem say "GYM", "RESTAURANT", "FASHION", or "ART GALLERY".

In the book "Möö La La Alışverişe Çıkan İnek" (Shaw, 2020), the text of the main character Möö La La and the bull's speech given in quotation marks with the photo of the character on the page, without a narrator's expression (like he said, said), provides the representation of the speech in the book.

The "hmmmm" voices of the teacher and Vashti, who are among the characters in the book "Nokta" (Reynold, 2020a), and the teacher's "Aaa" surprise voice in the text are evaluated in the category of voice in the text.

It is seen that the ninth page of the book "Ben Kitap" (Sonmaz, 2021) contains letters from different alphabets. This situation is considered an indicator of the letter in isolation category in the book.

The titles in the book "Beril Kendi Resmini Yapıyor" (Roca and Isern, 2019) are written from left to right, but curved, from top to bottom or from bottom to top, and the names of some images are written just below the image, separating it from the other text.

It has been found that the signs, labels, or sounds in the book "Postacı Fare'nin Bir Günü" (Dubuc, 2020) are in a different font than the rest of the text, and these words are usually written in bold, capital letters, or a different color.

\section{Conclusion}

Six books have only one print salient feature, but the other books have more than one feature. While 52 
of the books are in the font changes category, 29 books are in the category of bold or unique fonts. Thus, it can be inferred that the text in children's picture books provides more support for early print awareness. In addition, many books are in the categories of environmental print, labels, and visible sound. Therefore, it is observed that the illustrations are as important as the text in children's picture books in order to support knowledge about early literacy awareness and also print. There is a need for future research to expand the use of this strategy in read-aloud activities and to increase the quality of children's picture books that have print salient features. 